\title{
Lymphopenia and mortality among patients undergoing coronary angiography: Long-term follow-up study
}

\author{
Barak Zafrir ${ }^{1,2}$, Sliman Hussein ${ }^{1}$, Ronen Jaffe ${ }^{1,2}$, \\ Ofra Barnett-Griness ${ }^{3,4}$, Walid Saliba ${ }^{2,4}$ \\ ${ }^{1}$ Department of Cardiology, Lady Davis Carmel Medical Center, Haifa, Israel \\ ${ }^{2}$ Faculty of Medicine, Technion, Israel institute of Medicine, Haifa, Israel \\ ${ }^{3}$ Statistical Unit, Lady Davis Carmel Medical Center, Haifa, Israel \\ ${ }^{4}$ Department of Community Medicine and Epidemiology, \\ Lady Davis Carmel Medical Center, Haifa, Israel
}

\begin{abstract}
Background: Lymphopenia is associated with adverse prognosis in chronic disease states that are related to immune dysregulation. We aimed to determine the association between lymphopenia and mortality in patients presenting to coronary angiography and investigate whether elevated red blood cell distribution width (RDW), an established cardiovascular prognostic marker, further refines risk stratification.
\end{abstract}

Methods: Retrospective analysis of patients undergoing coronary angiography for evaluation or treatment of coronary artery disease between 2003 and 2018. Mortality risk associated with relative $(1000-1500 / \mu L)$ or severe $(<1000 / \mu L)$ lymphopenia was analyzed using adjusted Cox proportional hazards regression models.

Results: Overall, 15,179 patients aged $65 \pm 12$ years underwent coronary angiography. During a median follow-up of 8 years, 4253 patients died. Compared to normal lymphocyte count, the adjusted hazard ratio (HR) for mortality was 1.31 (95\% confidence interval [CI] 1.21-1.41) and 1.97 (95\% CI 1.75-2.22) for relative and severe lymphopenia, respectively. The increase in mortality associated with severe lymphopenia was significant in patients presenting in the non-acute setting (HR 2.18, 95\% CI 1.74-2.73), ST-segment elevation myocardial infarction (STEMI) (HR 1.59, 95\% CI 1.15-2.21), or unstable angina/non-STEMI (HR 2.00, 95\% CI 1.70-2.34); p-value for interaction 0.626. The association of lymphopenia with mortality remained significant after additional adjustment to RDW. High $R D W(>14.5 \%)$ was associated with reduced survival, and it improved the predictive accuracy of lymphocytes count with an increase in Harrell's Concordance statistic from $0.634(S E=0.005)$ to $0.672(S E=0.005), p<0.001$.

Conclusions: Lymphopenia is associated with increased risk of mortality during long-term follow-up in patients undergoing coronary angiography, regardless of the coronary presentation. High RDW may enhance the predictive ability of lymphopenia. (Cardiol J 2022; 29, 4: 637-646)

Key words: lymphopenia, coronary angiography, mortality, prognosis, red cell distribution width

Address for correspondence: Barak Zafrir, MD, FESC, FACC, Cardiovascular Department, Lady Davis Carmel Medical Center, 7 Michal St., Haifa, Israel, tel/fax: +972-48250801/916, e-mail: barakzmd@gmail.com

Received: 19.06.2020 Accepted: 12.10.2020 Early publication date: 26.10.2020

This article is available in open access under Creative Common Attribution-Non-Commercial-No Derivatives 4.0 International (CC BY-NC-ND 4.0) license, allowing to download articles and share them with others as long as they credit the authors and the publisher, but without permission to change them in any way or use them commercially. 


\section{Introduction}

Lymphopenia was demonstrated in observational studies to be associated with malignancies, infections, systemic autoimmune diseases, and worse clinical outcomes [1-5]. Early studies have shown that a low relative lymphocyte count, measured as the percentage of total leukocytes, is inversely associated with the risk of cardiovascular disease (CVD) states, particularly heart failure [6-10]. More recent findings further suggest that the measurement of absolute lymphocyte count by itself may risk stratify for mortality in the setting of the general population, especially when associated with other immunohematologic abnormalities [11, 12]. However, the extent to which absolute lymphopenia is associated with survival in patients with coronary artery disease (CAD) is less known [13]. In the current study, we aimed to investigate the association between absolute lymphocyte count and mortality in the real-world clinical practice of patients presenting to coronary angiography for evaluation and treatment of CAD, with both acute and non-acute coronary syndromes (ACS). In addition, we wished to examine whether elevated red blood cell distribution width (RDW), which has emerged as a useful prognostic parameter in CVDs, further refines risk prediction beyond lymphocyte count [14-17].

\section{Methods}

\section{Study population}

Retrospective analysis of the cardiac catheterization laboratory database at Carmel Medical Center, Haifa, Israel, between January 2000 and December 2018, was performed. Included were patients who were referred to coronary angiography for the assessment and/or treatment of CAD. Only the first angiography of each patient during the study period was included. This analysis was restricted to patients who are members of the Clalit Health Service (CHS), the largest non-for-profit health care provider in Israel, for whom we had full access to outcomes data during follow-up and other variables that were not originally collected at the time of coronary angiography. Patients with elevated lymphocyte count $>5000 / \mu \mathrm{L}$ and patients in whom laboratory values of white blood cells and red cell distribution width (RDW) counts in the year prior to angiography were unavailable were excluded. Final study population included 15,179 patients.

The study population was classified into three groups of angiographic indications: (a) unsta- ble angina pectoris (UAP) or acute non-ST-segment elevation myocardial infarction (NSTEMI), (b) acute ST-segment elevation myocardial infarction (STEMI), and (c) evaluation and/or treatment of CAD with stable clinical presentation (nonACS). The primary study endpoint was long-term mortality. The cause of death was not consistently available, and therefore we included all-cause and not cardiovascular death. Data on vital status was retrieved from the Ministry of the Interior. Cohort participants were followed up until reaching the occurrence of study outcome or end of follow-up in December 2019, whichever came first.

The study database was approved by Carmel Medical Center Ethics Committee with waiving of the need for individual patient consent due to the retrospective nature of the study.

\section{Study variables and definition of terms}

Demographic data, clinical variables, risk factors, and comorbidities were most often prospectively collected from patients' medical files at the time of coronary angiography. Data that was not originally collected were retrieved from computerized database of CHS. The results of all complete blood cell counts performed during the year prior to the date of coronary angiography were retrieved from the CHS laboratory database. We used 1-year median levels to calculate the absolute lymphocyte count, neutrophil-to-lymphocyte ratio (NLR), and RDW, in order to assess their association with mortality. The absolute lymphocyte count was evaluated in three ways: (a) classification to normal lymphocyte count $>1500 / \mu \mathrm{L}$ (reference category); relative lymphopenia $1000-1500 / \mu \mathrm{L}$; severe lymphopenia $<1000 / \mu \mathrm{L}$, (b) quintiles of lymphocyte count with the highest quintile serving as reference, and (c) lymphocyte levels included in the model as a continuous variable. For the purpose of the current study, elevated RDW values were defined as $>14.5 \%$ [15].

\section{Data analysis}

Continuous data are reported as means and standard deviation or median and interquartile range (IQR), and categorical variables as numbers and percentages. One-way ANOVA test was used to compare continuous variables and $\chi^{2}$ to compare categorical variables. For each lymphocytes group, the number of events and the incidence rates of death per 100 person-years were calculated. Median follow-up was estimated using subjects alive at end of follow-up. Kaplan-Meier curves were used to estimate the long-term cumulative incidence of 
death according to the lymphocyte count categories, with comparison between curves performed using the log-rank test. The association between lymphocyte count and mortality over time was evaluated using Cox proportional hazards regression models to estimate the hazard ratio (HR) with 95\% confidence interval (CI), using three models adjusting for (a) age and gender, (b) multivariable adjustment including demographics, clinical characteristics, and baseline comorbidities, and (c) with additional adjustment to RDW.

We performed additional sensitivity analyses by repeating the multivariable models using the most adjacent lymphocyte count performed before coronary angiography instead of median 1-year levels, and by further adjusting the multivariable model to NLR, a marker of inflammation that was found to be independently associated with increased risk of mortality in various cardiovascular diseases [18]. Exploratory analysis was performed by examining the association between lymphopenia and all-cause mortality stratified by the acuity of coronary presentation (STEMI, UAP/NSTEMI, non-ACS), and according to age decades, with calculation of $\mathrm{p}$-values for interaction between subgroups.

In order to further assess the association of lymphocyte count with mortality, absolute lymphocyte count was additionally modeled as a continuous variable. First, a linearity assumption on the relationship between lymphocyte count and mortality was tested using a likelihood ratio test, comparing two nested Cox regression models: one including only linear effect and the second including also quadratic and cubic terms, and the non-linearity was detected. Then, for graphical presentation of the association, a smoothed plot of adjusted HR (relative to a reference value of $2000 / \mu \mathrm{L}$, the overall median count) was estimated along with point-wise $95 \%$ CI. For this purpose, the lymphocyte count was flexibly modeled in a Cox regression using a restricted cubic spline function with five knots corresponding to the $5 \%, 25 \%$, $50 \%, 75 \%$, and $95 \%$ percentiles of lymphocyte count [19]. We repeated the analysis separately for each of the three clinical presentation types: STEMI, UAP/NSTEMI, and non-ACS, and we tested the interaction between presentation type and lymphocyte count.

To assess the predictive accuracy of lymphocyte counts with and without the addition of RDW into a Cox regression model, Harrell's concordance statistic was used, as implemented in the R survival package [20]. Concordance statistic along with standard error (SE) were presented, and further compared using appropriate $Z$ contrast.

The results were considered statistically significant when the two-sided p-value was $<0.05$. SPSS statistical software version 20.0, SAS version 9.4 software, and MEDCALC version 16.8.4 were used to perform all statistical analyses.

\section{Results}

A total of 15,179 patients undergoing coronary angiography for evaluation and/or treatment of CAD were included in the study. Their mean age was $65 \pm 12$ years, and $72 \%$ were males. Baseline patients' characteristics are shown in Table 1, classified according to lymphocyte category (normal lymphocyte count, relative lymphopenia, and severe lymphopenia). Compared to those with normal lymphocyte count, subjects with lymphopenia were older. The prevalence of chronic kidney disease, hypertension, prior cancer, vascular disease, congestive heart failure, chronic obstructive lung disease, RDW levels, as well as presentation with $\mathrm{ACS}$, increased with the reduction in lymphocyte count. In contrast, lymphopenia was associated with lower rates of hyperlipidemia, obesity, smoking, and Arab ethnicity.

\section{The association between lymphopenia and mortality}

Overall, 4253 (28\%) patients died during a median follow-up of 8 years (IQR 4-12.2 years). Crude incidence rates of death increased progressively in patients with relative and severe lymphopenia compared to those with normal lymphocyte count, and in an inverse dose-response manner across lymphocyte quintiles: $7.16,4.12$, $3.20,2.76$, and 2.37 events per 100 person-years, respectively (Table 2). Kaplan-Meier plots displaying the distribution of time to mortality by the three lymphocyte categories are presented in Figure 1 (log rank $\mathrm{p}<0.001)$. In a multivariable Cox proportional hazard regression analysis, the adjusted HR (95\% CI) for long-term mortality was 1.31 (1.21-1.41) for relative lymphopenia and 1.97 (1.75-2.22) for severe lymphopenia, compared to subjects with normal lymphocyte counts (Table 2). In addition, compared to the highest lymphocyte quintile, the HRs for mortality increased in a graded manner ( $\mathrm{p}$ for trend across quintiles $<0.001)$ and when analyzed as a continuous variable with an HR (95\% CI) of 1.23 (1.17-1.29), $\mathrm{p}<0.001$ for each 100-lymphocyte cell count decrease. However, lymphocyte count appears 
Cardiology Journal 2022, Vol. 29, No. 4

Table 1. Patient characteristics according to lymphocyte count.

\begin{tabular}{|c|c|c|c|c|c|}
\hline Variable & $\begin{array}{c}\text { Overall } \\
\text { population } \\
N=15179\end{array}$ & $\begin{array}{c}\text { Normal } \\
\text { lymphocyte count } \\
1500-5000 / \mu \mathrm{L} \\
\mathrm{N}=11875(78.2 \%)\end{array}$ & $\begin{array}{c}\text { Relative } \\
\text { lymphopenia } \\
1000-1500 / \mu \mathrm{L} \\
\mathrm{N}=2739(18 \%)\end{array}$ & $\begin{array}{c}\text { Severe } \\
\text { Iymphopenia } \\
<1000 / \mu \mathrm{L} \\
\mathrm{N}=565(3.7 \%)\end{array}$ & $\mathbf{P}$ \\
\hline Age [years] & $65 \pm 12$ & $64 \pm 11$ & $70 \pm 11$ & $73 \pm 11$ & $<0.001$ \\
\hline Women & $4359(28.7 \%)$ & $3448(29 \%)$ & $778(28.4 \%)$ & $133(23.5 \%)$ & 0.017 \\
\hline Hypertension & $11088(73 \%)$ & $8542(71.9 \%)$ & $2097(76.6 \%)$ & $449(79.5 \%)$ & $<0.001$ \\
\hline Hyperlipidemia & $11021(72.6 \%)$ & $8696(73.2 \%)$ & $1945(71 \%)$ & $380(67.3 \%)$ & 0.001 \\
\hline Smoker & $3495(23 \%)$ & $3114(26.2 \%)$ & $327(11.9 \%)$ & $54(9.6 \%)$ & $<0.001$ \\
\hline Diabetes & $5972(39.3 \%)$ & $4703(39.6 \%)$ & $1045(38.2 \%)$ & $24(39.6 \%)$ & 0.370 \\
\hline Ethnicity (Arab) & $2801(18.5 \%)$ & $2438(20.5 \%)$ & $300(11 \%)$ & $63(11.2 \%)$ & $<0.001$ \\
\hline Obesity & $4726(31.1 \%)$ & $3929(33.1 \%)$ & $672(24.5 \%)$ & $125(22.1 \%)$ & $<0.001$ \\
\hline Old myocardial infarction & $8127(53.5 \%)$ & $6163(51.9 \%)$ & $1600(58.4 \%)$ & $364(64.4 \%)$ & $<0.001$ \\
\hline Chronic kidney disease & $1651(10.9 \%)$ & $1002(8.4 \%)$ & $492(18 \%)$ & $157(27.8 \%)$ & $<0.001$ \\
\hline Creatinine $>1.4 \mathrm{mg} / \mathrm{dL}$ & $1302(8.6 \%)$ & $769(6.5 \%)$ & $386(14.1 \%)$ & $147(26 \%)$ & $<0.001$ \\
\hline PVD & $992(6.5 \%)$ & $681(5.7 \%)$ & $252(9.2 \%)$ & $59(10.4 \%)$ & $<0.001$ \\
\hline CABG & 1725 (11.4\%) & $1270(10.7 \%)$ & $368(13.4 \%)$ & $87(15.4 \%)$ & $<0.001$ \\
\hline ACS & $8077(53.2 \%)$ & $6080(51.2 \%)$ & $1611(58.8 \%)$ & $386(68.3 \%)$ & $<0.001$ \\
\hline Cancer & $1684(11.1 \%)$ & $10429(8.8 \%)$ & $506(18.5 \%)$ & $136(24.1 \%)$ & $<0.001$ \\
\hline Heart failure & $2843(10.7 \%)$ & $1892(15.9 \%)$ & $725(26.5 \%)$ & $226(40 \%)$ & $<0.001$ \\
\hline COPD & $1088(7.2 \%)$ & 799 (6.7\%) & $225(8.2 \%)$ & $64(11.3 \%)$ & $<0.001$ \\
\hline RDW median (IQR) & $13.7(13.2-14.4)$ & 13.6 (13.1-14.3) & 14.0 (13.3-14.7) & $14.4(13.6-15.6)$ & $<0.001$ \\
\hline WBC median (IQR) & $7.9(6.6-9.4)$ & $8.1(7.0-9.6)$ & $6.8(5.7-8.1)$ & $6.7(5.4-8.4)$ & $<0.001$ \\
\hline
\end{tabular}

ACS - acute coronary syndrome; CABG — coronary artery bypass graft surgery; COPD — chronic obstructive pulmonary disease; IQR interquartile range; PVD — peripheral vascular disease; RDW — red cell distribution width; WBC — white blood cells

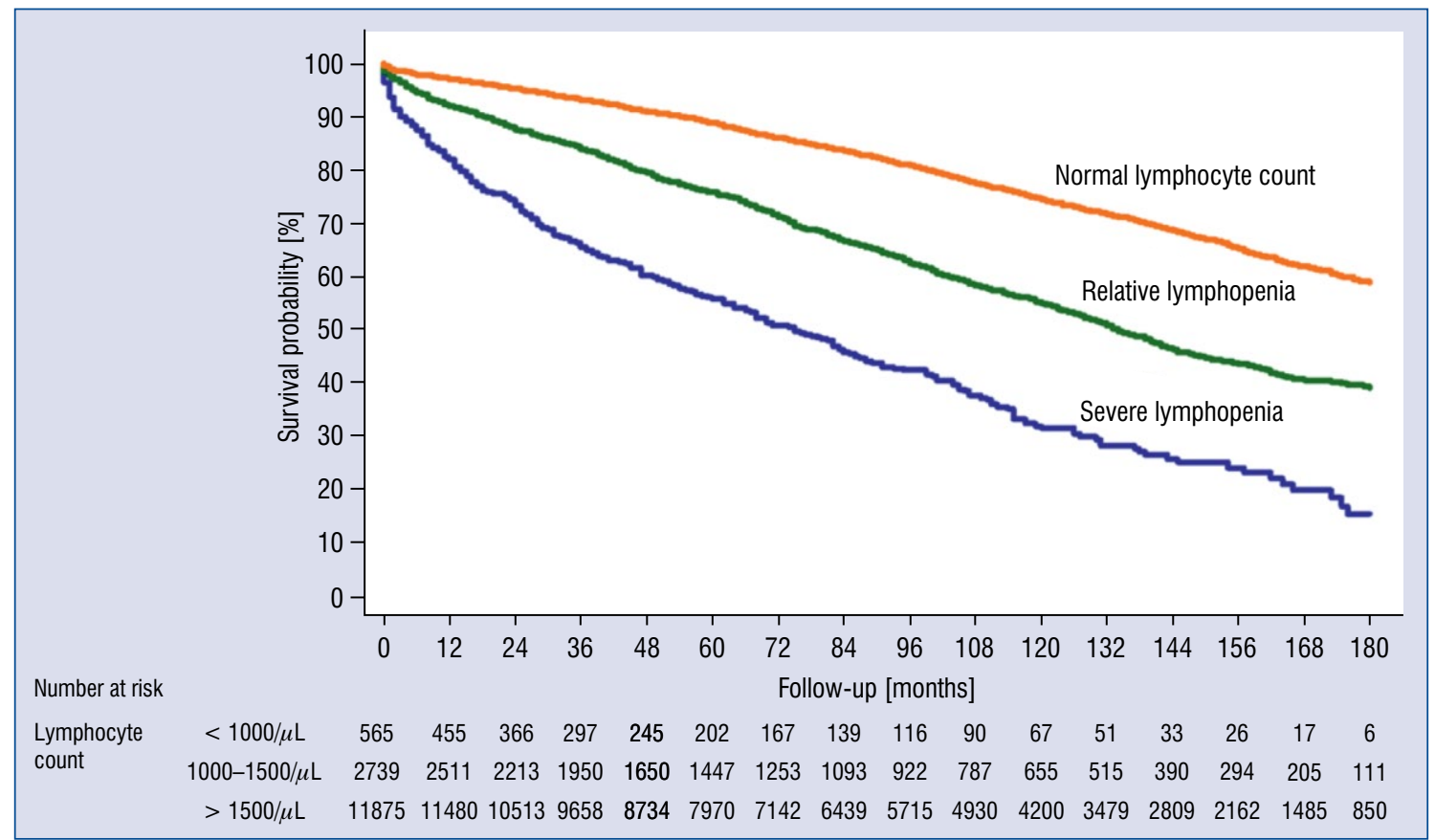

Figure 1. Long-term survival as a function of lymphocyte count. 
Table 2. Crude incidence rates and multivariate Cox proportional regression models for the association between lymphocyte counts and long-term mortality.

\begin{tabular}{|c|c|c|c|c|c|}
\hline Lymphocyte count & $\begin{array}{l}\text { No. of death/ } \\
\text { /patients }(\%)\end{array}$ & $\begin{array}{c}\text { Incidence rate } \\
\text { per } 100 \text { person- } \\
\text {-years }\end{array}$ & $\begin{array}{l}\text { Age and gender } \\
\text { adjusted HR }\end{array}$ & $\begin{array}{l}\text { Multivariable* } \\
\text { adjusted HR }\end{array}$ & $\begin{array}{c}\text { Multivariable }+ \\
\text { RDW adjusted } \\
\text { HR }\end{array}$ \\
\hline \multicolumn{6}{|l|}{ Three categories } \\
\hline $\begin{array}{l}\text { Normal lymphocyte } \\
\text { count }\end{array}$ & $\begin{array}{l}2864 / 11875 \\
(24.1 \%)\end{array}$ & 3.04 & Reference & Reference & Reference \\
\hline Relative lymphopenia & $\begin{array}{c}1073 / 2739 \\
(39.2 \%)\end{array}$ & 6.12 & $\begin{array}{c}1.41(1.32-1.52) \\
P<0.001\end{array}$ & $\begin{array}{c}1.31(1.21-1.41) \\
P<0.001\end{array}$ & $\begin{array}{c}1.26(1.17-1.36) \\
P<0.001\end{array}$ \\
\hline Severe lymphopenia & $\begin{array}{l}316 / 565 \\
(55.9 \%)\end{array}$ & 12.32 & $\begin{array}{c}2.47(2.19-2.78) \\
P<0.001\end{array}$ & $\begin{array}{c}1.97(1.75-2.22) \\
P<0.001\end{array}$ & $\begin{array}{c}1.84(1.63-2.07) \\
P<0.001\end{array}$ \\
\hline \multicolumn{6}{|l|}{ Quintiles } \\
\hline $\mathrm{Q} 1<1495 / \mu \mathrm{L}$ & $1304 / 3031(43 \%)$ & 7.16 & $\begin{array}{c}1.64(1.49-1.82) \\
P<0.001\end{array}$ & $\begin{array}{c}1.47(1.33-1.63) \\
P<0.001\end{array}$ & $\begin{array}{c}1.42(1.28-1.57) \\
P<0.001\end{array}$ \\
\hline 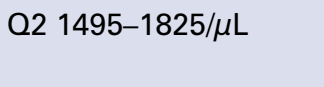 & $885 / 3034(29.2 \%)$ & 4.12 & $\begin{array}{c}1.13(1.01-1.25) \\
P=0.027\end{array}$ & $\begin{array}{c}1.10(0.99-1.23) \\
P=0.071\end{array}$ & $\begin{array}{c}1.10(0.99-1.23) \\
P=0.068\end{array}$ \\
\hline 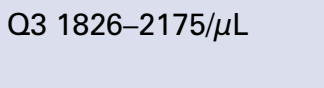 & $756 / 3037(24.9 \%)$ & 3.20 & $\begin{array}{c}1.01(0.91-1.13) \\
P=0.846\end{array}$ & $\begin{array}{c}(0.92-1.14) \\
P=0.715\end{array}$ & $\begin{array}{l}(0.92-1.15) \\
P=0.612\end{array}$ \\
\hline 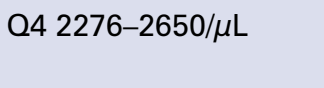 & $693 / 3038(22.8 \%)$ & 2.76 & $\begin{array}{c}0.97(0.87-1.08) \\
P=0.515\end{array}$ & $\begin{array}{c}0.97(0.87-1.09) \\
P=0.616\end{array}$ & $\begin{array}{c}0.98(0.88-1.09) \\
P=0.685\end{array}$ \\
\hline $\mathrm{Q} 5>2650 / \mu \mathrm{L}$ & $615 / 3039(20.2 \%)$ & 2.37 & Reference & Reference & Reference \\
\hline \multicolumn{6}{|l|}{ Continuous } \\
\hline \multicolumn{2}{|c|}{$\begin{array}{l}\text { HR is for each decrease of } \\
100 / \mu \mathrm{L} \text { in lymphocyte count }\end{array}$} & & $\begin{array}{c}1.32(1.25-1.38) \\
P<0.001\end{array}$ & $\begin{array}{c}1.23(1.17-1.29) \\
P<0.001\end{array}$ & $\begin{array}{c}1.20(1.14-1.26) \\
P<0.001\end{array}$ \\
\hline
\end{tabular}

HR - hazard ratio; $\mathrm{Q}$ - quintile; RDW - red cell distribution width

Normal lymphocyte count $>1500 / \mu \mathrm{L}$; relative lymphopenia $1000-1500 / \mu \mathrm{L}$; severe lymphopenia $<1000 / \mu \mathrm{L}$

*Adjusted for age, gender, ethnicity, hypertension, hyperlipidemia, smoking, diabetes, chronic kidney disease, obesity, cancer, chronic obstructive pulmonary disease, heart failure, peripheral vascular disease, previous myocardial infarction, acute coronary syndrome

to have a nonlinear reversed J-shaped relationship with all-cause mortality ( $\mathrm{p}$ for nonlinearity $<0.0001$ ). A smoothed plot of adjusted HR (relative to the overall median lymphocyte value of $2000 / \mu \mathrm{L})$ is presented in Figure 2.

The magnitude of the adjusted HR (95\% CI) for death associated with severe lymphopenia decreased with increasing age ( $\mathrm{p}$ for interaction $<0.001)$ : $3.25(2.24-4.71)$ in those aged $\leq 60$ years, $2.32(1.73-3.12)$ in ages $>60$ to 70 years, $1.84(1.53-2.22)$ in ages $>70$ to 80 years, and 1.75 (1.41-2.17) in patients aged $>80$ years (Table 3 ).

We reached similar results performing sensitivity analysis, in which the association with mortality was evaluated using the most recent lymphocyte count tested before angiography instead of the median values of all lymphocyte counts in the year prior to angiography (in this period a median of three tests [IQR $2-5$ tests] were available for each patient): multivariable adjusted HR (95\% CI) for mortality was 1.65 (1.48-1.83), $\mathrm{p}<0.001$ for severe lymphopenia and 1.29 (1.20-1.39), $\mathrm{p}<0.001$ for relative lymphopenia. Moreover, the

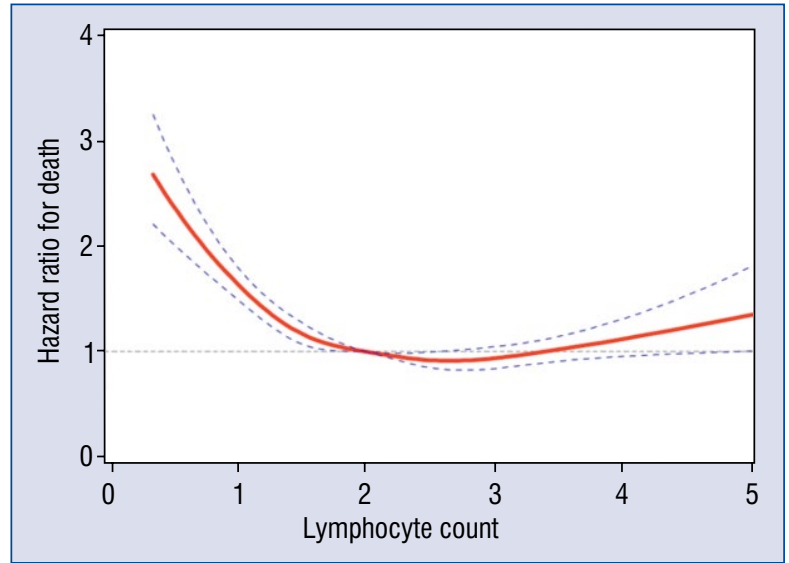

Figure 2. Association between lymphocyte count and adjusted hazard ratio for mortality based on restricted cubic spline model, in the overall population.

significant association of lymphopenia with mortality was retained after the addition of NLR to the multivariable model, both when added as median NLR levels: relative lymphopenia, HR 1.18 (95\% 
Table 3. Association of lymphocyte count with mortality according to age decades.

\begin{tabular}{|c|c|c|c|}
\hline $\begin{array}{l}\text { Age groups } \\
\text { [years] }\end{array}$ & $\begin{array}{c}\text { Normal lymphocyte count } \\
\text { Deaths/at risk (\%) } \\
\text { Adjusted* HR (95\% Cl) } \\
\text { P value }\end{array}$ & $\begin{array}{c}\text { Relative lymphopenia } \\
\text { Deaths/at risk (\%) } \\
\text { Adjusted* HR (95\% CI) } \\
\text { P value }\end{array}$ & $\begin{array}{c}\text { Severe lymphopenia } \\
\text { Deaths/at risk (\%) } \\
\text { Adjusted* HR ( } 95 \% \mathrm{CI}) \\
\text { P value }\end{array}$ \\
\hline$\leq 60$ & $\begin{array}{c}\text { 492/4632 }(10.6 \%) \\
\text { Reference }\end{array}$ & $\begin{array}{l}87 / 527(16.5 \%) \\
1.33(1.05-1.69) \\
P=0.017\end{array}$ & $\begin{array}{c}32 / 78(41 \%) \\
3.25(2.24-4.71) \\
\quad P<0.001\end{array}$ \\
\hline$>60$ to 70 & $\begin{array}{c}808 / 3768(21.4 \%) \\
\text { Reference }\end{array}$ & $\begin{array}{l}216 / 774(27.9 \%) \\
1.45(1.24-1.69) \\
P<0.001\end{array}$ & $\begin{array}{l}50 / 133(37.6 \%) \\
2.32(1.73-3.12) \\
\quad P<0.001\end{array}$ \\
\hline$>70$ to 80 & $\begin{array}{c}\text { 1078/2637 (40.9\%) } \\
\text { Reference }\end{array}$ & $\begin{array}{c}453 / 942(48.1 \%) \\
1.27(1.14-1.42) \\
P<0.001\end{array}$ & $\begin{array}{c}128 / 206(62.1 \%) \\
1.84(1.53-2.22) \\
P<0.001\end{array}$ \\
\hline$>80$ & $\begin{array}{l}\text { 486/838 (58\%) } \\
\text { Reference }\end{array}$ & $\begin{array}{l}317 / 496(63.9 \%) \\
1.23(1.06-1.42) \\
P=0.006\end{array}$ & $\begin{array}{l}106 / 148(71.6 \%) \\
1.75(1.41-2.17) \\
\quad P<0.001\end{array}$ \\
\hline
\end{tabular}

$\mathrm{Cl}$ - confidence interval; $\mathrm{HR}$ - hazard ratio

$\mathrm{P}$ for interaction between age and lymphocyte count $<0.001$

*Adjusted for age, gender, ethnicity, hypertension, hyperlipidemia, smoking, diabetes, chronic kidney disease, obesity, cancer, chronic obstructive pulmonary disease, heart failure, peripheral vascular disease, previous myocardial infarction, acute coronary syndrome

CI 1.10-1.28), $\mathrm{p}<0.001$ and severe lymphopenia, HR 1.45 (95\% CI 1.25-1.69), p < 0.001 or as NLR tertiles: relative lymphopenia, HR $1.11(95 \% \mathrm{CI}$ $1.02-1.20), \mathrm{p}=0.015$ and severe lymphopenia, $\mathrm{HR}$ 1.62 (95\% CI 1.42-1.84), $\mathrm{p}<0.001$.

\section{Lymphopenia and mortality, according to acuity of coronary presentation}

Similar to the overall population, crude incidence rates of death and adjusted HRs for mortality were higher in patients with relative lymphopenia, and more so in severe lymphopenia, compared to normal lymphocyte count, in each of the three coronary presentations (non-ACS, UAP/NSTEMI, or STEMI) (Table 4). Severe lymphopenia was associated with an adjusted HR $(95 \% \mathrm{CI})$ for mortality of $2.18(1.74-2.73)$ in patients with non-ACS, $2.00(1.70-2.34)$ in those with UAP/NSTEMI, and 1.59 (1.15-2.21) in patients presenting with acute STEMI. The p-value for interaction between lymphocyte count and coronary presentation in relation to mortality was non-significant $(\mathrm{p}=0.626)$.

Supplementary Figure S1 further presents a smoothed plot of adjusted HRs for mortality according the coronary presentations based on restricted cubic spline model.

\section{RDW and refinement of mortality risk}

Red blood cell distribution width levels were higher in patients with lymphopenia (Table 1). The independent association between lymphopenia and mortality remained significant after further adjustment for RDW in the multivariable model, both in the overall study population (Table 2 ) and when separately analyzed in the three categories of coronary presentation (model 2 in Table 4). Survival probabilities over time in each of the lymphocyte count categories (normal lymphocyte levels, relative lymphopenia, or severe lymphopenia) were lower in patients with high RDW levels $>14.5 \%$ compared to those with RDW levels $\leq 14.5 \%$ (Suppl. Fig. S2). The discrimination ability of the lymphocyte count for mortality was improved with the addition of RDW count; the Harrell's concordance statistic significantly increased from 0.634 $(\mathrm{SE}=0.005)$ to $0.672(\mathrm{SE}=0.005), \mathrm{p}<0.001$ for the change in the concordance statistic. The addition of RDW to lymphocyte count increased the discriminatory capacity for mortality in each of the three coronary presentations (STEMI: from $0.623[\mathrm{SE}=0.014]$ to $0.665[\mathrm{SE}=0.0014]$; $\mathrm{UAP} /$ /NSTEMI: from 0.646 [SE $=0.007$ ] to 0.688 [SE $=0.006]$; non-ACS: from 0.610 [SE $=0.008]$ to 0.653 [SE $=0.008$ ], $\mathrm{p}<0.001$ for all comparisons).

\section{Discussion}

In the present study we analyzed the association between absolute lymphocyte count and longterm mortality in patients presenting to coronary angiography in both the acute and non-acute setting. Lymphopenia, especially when severe, was associated with increased long-term mortality, even after adjusting to chronic disease states such 
Table 4. Association of lymphocyte count with mortality, according to coronary presentation.

\begin{tabular}{|c|c|c|c|}
\hline Coronary presentation & Normal lymphocyte count & Relative lymphopenia & Severe Iymphopenia \\
\hline \multicolumn{4}{|l|}{ Non-ACS } \\
\hline Deaths/at risk (\%) & $1288 / 5795(22.2 \%)$ & $381 / 1128(33.8 \%)$ & $86 / 179(48 \%)$ \\
\hline \multirow[t]{2}{*}{ Model 1} & Reference & $1.30(1.15-1.46)$ & $2.18(1.74-2.73)$ \\
\hline & & $P<0.001$ & $P<0.001$ \\
\hline \multirow[t]{2}{*}{ Model 2} & Reference & $1.25(1.11-1.41)$ & $1.94(1.55-2.44)$ \\
\hline & & $P<0.001$ & $P<0.001$ \\
\hline \multicolumn{4}{|l|}{ UAP/NSTEMI } \\
\hline Deaths/at risk (\%) & $1267 / 4753(26.7 \%)$ & $561 / 1292(43.4 \%)$ & $185 / 286(64.7 \%)$ \\
\hline \multirow[t]{2}{*}{ Model 1} & Reference & $1.39(1.25-1.54)$ & $2.00(1.70-2.34)$ \\
\hline & & $P<0.001$ & $P<0.001$ \\
\hline \multirow[t]{2}{*}{ Model 2} & Reference & $1.33(1.20-1.48)$ & $1.81(1.54-2.12)$ \\
\hline & & $P<0.001$ & $P<0.001$ \\
\hline \multicolumn{4}{|l|}{ STEMI } \\
\hline Deaths/at risk (\%) & $309 / 1327(23.3 \%)$ & $131 / 319(41.1 \%)$ & $45 / 100(45 \%)$ \\
\hline \multirow[t]{2}{*}{ Model 1} & Reference & $1.10(0.89-1.37)$ & $1.59(1.15-2.21)$ \\
\hline & & $P=0.370$ & $P=0.005$ \\
\hline \multirow[t]{2}{*}{ Model 2} & Reference & $1.05(0.84-1.30)$ & $1.54(1.11-2.14)$ \\
\hline & & $P=0.693$ & $P<0.001$ \\
\hline
\end{tabular}

ACS - acute coronary syndrome; NSTEMI — non-ST-segment elevation myocardial infarction; STEMI - ST-segment elevation myocardial infarction; UAP - unstable angina pectoris

$\mathrm{P}$ for interaction between lymphocyte count and coronary presentation $=0.626$

Model 1: Hazard ratios (95\% confidence intervals) adjusted for age, gender, ethnicity, hypertension, hyperlipidemia, smoking, diabetes,

chronic kidney disease, obesity, cancer, chronic obstructive pulmonary disease, heart failure, peripheral vascular disease, previous myocardial infarction

Model 2: Hazard ratios (95\% confidence intervals) adjusted as model $1+$ red cell distribution width

as cancer, heart failure, and vascular diseases, and regardless of the acuity of the coronary presentation. The magnitude of the increase in the risk of death associated with severe lymphopenia was more prominent in younger age groups. Moreover, elevated RDW levels were additively associated with reduced survival, and further refined risk prediction improving the discriminatory capacity of absolute lymphocyte count for mortality.

Lymphopenia is a common hematological finding observed in systemic inflammatory states, malignancies, and autoimmune diseases [1-5]. Early studies have shown that a low relative lymphocyte count, measured as the percentage of total leukocytes, is predictive of adverse outcomes in CVD states, particularly heart failure [6-10]. Relatively few studies have evaluated absolute lymphocyte count as a prognostic biomarker, demonstrating its ability to stratify risk for mortality in the general population [11, 12]. Our findings extend the prognostic value of absolute lymphopenia to patients undergoing coronary angiography for evaluation and/or treatment of
CAD with both ACS and non-ACS. The increase in mortality seemed to be less pronounced in patients presenting with acute STEMI, although the interaction between lymphocyte count and coronary presentation was not statistically significant. Only a few analyses of very small-scale have evaluated the prognostic significance of lymphopenia in patients with CAD, including stable clinical presentation [21], unstable angina [22], mechanical complications after myocardial infarction [23], and no-reflow phenomenon [24]. In addition, total white blood cell count was shown to be an independent predictor of death and myocardial infarction in patients with, or at high risk of, $\mathrm{CAD}$, with greater predictive ability provided by high neutrophil or low lymphocyte counts [13]. In the current analysis the increased mortality risk associated with lymphopenia remained significant after adjustment to NLR, demonstrating the independent predictive ability of absolute lymphopenia, which is more intuitive for bedside calculation than NLR.

Several mechanistic pathways may connect lymphopenia to adverse prognosis in CAD. Lymphocytes have been suggested to play a role in the 
modulation of the inflammatory response throughout the atherosclerotic process [25]. In response to physiologic stress there is a release of cortisol, catecholamines, and proinflammatory cytokines, which may lead to lymphopenia [26-28]. Activation of the immune system during myocardial ischemia or infarction may be accompanied by an increase of lymphocyte apoptosis, which was shown to be present in atherosclerotic lesions and becomes increasingly frequent with the development and destabilization of the atherosclerotic plaque [29]. Lymphopenia may also be aggravated by redistribution of $T$ cells from the circulation to lymphoid tissues [30]; it may induce compensatory proliferation of antigen-experienced $\mathrm{T}$ cells, which could increase the risk of cardiovascular disease [31]. On the other hand, an optimal lymphocyte count may reflect an immune system that is more capable of providing protection against cardiovascular diseases [12].

Lymphocyte count is known to decline with age [32], and this was also observed in the current analysis. Nevertheless, we found a higher relative risk for mortality associated with severe lymphopenia in younger age groups, with a significant interaction between age and lymphocyte count in the context of mortality during long-term followup. A similar trend was recently shown by Warny et al. [11] in the setting of the general population; it was suggested that additional factors including poor immune surveillance, blood transfusions, and iatrogenic causes such as medications might contribute to the difference in mortality risk between age groups.

Red blood cell distribution width is a measure of red cell size variability. Its use in the clinical setting is mainly for the differential diagnosis of micro- and normocytic anemias [33]. However, in recent years multiple studies have shown significant associations between RDW and clinical outcomes in a variety of populations, particularly cardiovascular morbidity and mortality [34, 35]. An elevated RDW may reflect chronic inflammation, ultimately leading to altered iron homeostasis and erythropoietin resistance. Associations between RDW, inflammatory markers, and impaired iron mobilization were demonstrated in heart failure [36, 37]. In the United Kingdom Biobank study, examining healthy volunteers, the incidence of $\mathrm{CAD}$ and all-cause mortality began to increase with RDW values $>13 \%$ and was the highest (3-fold higher) in participants with RDW value $>15 \%$ [38]. A meta-analysis of 21 studies concluded that high RDW levels are associated with increased risk of mortality and cardiovascular events also in patients with established CAD [39]. Zidar et al. [12] recently demonstrated in the setting of the general population that the risks associated with abnormal immunohematologic parameters including lymphopenia, $\mathrm{RDW}$, and C-reactive protein may be synergistic with each other. Our findings are in line with these results, demonstrating improved risk prediction in patients with CAD when both lymphocytes and RDW levels are taken into account.

\section{Strengths and limitations}

Strengths of the current analysis include the large number of CAD patients investigated with both acute and non-acute presentations and the long follow-up period. In addition, the classification of lymphocytes as both categorical and continuous variables may have reduced potential bias. Several limitations should also be noted. The study does not prove a causal relation between lymphopenia and mortality, due to its retrospective observational design. In addition, although significant adjustment was made for confounding variables including malignancies, heart failure, and other vascular diseases, we cannot exclude residual confounding. We did not account for infectious causes or autoimmune diseases that are known to be associated with inflammatory markers. Parameters of immune activation such as C-reactive protein levels were not available, although we did adjust our data to NLR, an indicator of inflammation and oxidative stress that did not neutralize the independent association of lymphopenia with mortality. Moreover, we used median levels of all lymphocyte counts in the year prior to angiography, and therefore our results may not reflect the association of lymphocyte count during ACS with mortality. However, we did perform sensitivity analysis using the most recent lymphocyte count tested before angiography, achieving similar results. Finally, causes of death were not available, and therefore we could not evaluate the association of lymphopenia with specific causes of death.

\section{Conclusions}

Absolute lymphopenia, especially when severe, may identify patients presenting to coronary angiography who are at higher risk for mortality during long-term follow-up. This association, observed in both acute and non-acute coronary presentations, was more significant in younger age groups and was aggravated in patients with elevated RDW levels enhancing the predictive 
ability of lymphopenia. Routinely obtained immunohematologic blood indices have potential utility in clinical practice as biomarkers for long-term risk prediction in patients with CAD.

\section{Conflict of interest: None declared}

\section{References}

1. Fogar P, Sperti C, Basso D, et al. Decreased total lymphocyte counts in pancreatic cancer: an index of adverse outcome. Pancreas. 2006; 32(1): 22-28, doi: 10.1097/01. mpa.0000188305.90290.50, indexed in Pubmed: 16340740.

2. Ray-Coquard I, Cropet C, Van Glabbeke M, et al. Lymphopenia as a prognostic factor for overall survival in advanced carcinomas, sarcomas, and lymphomas. Cancer Res. 2009; 69(13): 5383-5391, doi: 10.1158/0008-5472.CAN-08-3845, indexed in Pubmed: 19549917.

3. Saroha S, Uzzo RG, Plimack ER, et al. Lymphopenia is an independent predictor of inferior outcome in clear cell renal carcinoma. J Urol. 2013; 189(2): 454-461, doi: 10.1016/j. juro.2012.09.166, indexed in Pubmed: 23041457.

4. Hepburn AL, Narat S, Mason JC. The management of peripheral blood cytopenias in systemic lupus erythematosus. Rheumatology (Oxford). 2010; 49(12): 2243-2254, doi: 10.1093/rheumatology/keq269, indexed in Pubmed: 20823093.

5. Warny M, Helby J, Nordestgaard BG, et al. Lymphopenia and risk of infection and infection-related death in 98,344 individuals from a prospective Danish population-based study. PLoS Med. 2018; 15(11): e1002685, doi: 10.1371/journal.pmed.1002685, indexed in Pubmed: 30383787.

6. Rudiger A, Burckhardt OA, Harpes P, et al. The relative lymphocyte count on hospital admission is a risk factor for long-term mortality in patients with acute heart failure. Am J Emerg Med. 2006; 24(4): 451-454, doi: 10.1016/j.ajem.2005.10.010, indexed in Pubmed: 16787804.

7. Ommen SR, Hodge DO, Rodeheffer RJ, et al. Predictive power of the relative lymphocyte concentration in patients with advanced heart failure. Circulation. 1998; 97(1): 19-22, doi: 10.1161/01. cir.97.1.19, indexed in Pubmed: 9443426.

8. Acanfora D, Gheorghiade M, Trojano L, et al. Relative lymphocyte count: a prognostic indicator of mortality in elderly patients with congestive heart failure. Am Heart J. 2001; 142(1): 167-173, doi: 10.1067/mhj.2001.115792, indexed in Pubmed: 11431674.

9. Huehnergarth KV, Mozaffarian D, Sullivan MD, et al. Usefulness of relative lymphocyte count as an independent predictor of death/urgent transplant in heart failure. Am J Cardiol. 2005; 95(12): 1492-1495, doi: 10.1016/j.amjcard.2005.02.022, indexed in Pubmed: 15950581.

10. Vaduganathan M, Ambrosy AP, Greene SJ, et al. Predictive value of low relative lymphocyte count in patients hospitalized for heart failure with reduced ejection fraction: insights from the EVEREST trial. Circ Heart Fail. 2012; 5(6): 750-758, doi: 10.1161/CIRCHEARTFAILURE.112.970525, indexed in Pubmed: 23051949.

11. Warny M, Helby J, Nordestgaard BG, et al. Incidental lymphopenia and mortality: a prospective cohort study. CMAJ. 2020; 192(2): E25-E33, doi: 10.1503/cmaj.191024, indexed in Pubmed: 31932337.
12. Zidar DA, Al-Kindi SG, Liu Y, et al. Association of lymphopenia with risk of mortality among adults in the US general population. JAMA Netw Open. 2019; 2(12): e1916526, doi: 10.1001/jamanetworkopen.2019.16526, indexed in Pubmed: 31790569.

13. Horne BD, Anderson JL, John JM, et al. Which white blood cell subtypes predict increased cardiovascular risk? J Am Coll Cardiol. 2005; 45(10): 1638-1643, doi: 10.1016/j.jacc.2005.02.054, indexed in Pubmed: 15893180.

14. Al-Najjar Y, Goode KM, Zhang J, et al. Red cell distribution width: an inexpensive and powerful prognostic marker in heart failure. Eur J Heart Fail. 2009; 11(12): 1155-1162, doi: 10.1093/eurjhf/ hfp147, indexed in Pubmed: 19926599.

15. Saliba W, Barnett-Griness O, Rennert G. Red cell distribution width and all-cause mortality in patients with atrial fibrillation: A cohort study. J Arrhythm. 2017; 33(1): 56-62, doi: 10.1016/j. joa.2016.06.001, indexed in Pubmed: 28217230.

16. Dabbah S, Hammerman H, Markiewicz W, et al. Relation between red cell distribution width and clinical outcomes after acute myocardial infarction. Am J Cardiol. 2010; 105: 312-317.

17. Arbel Y, Weitzman D, Raz R, et al. Red blood cell distribution width and the risk of cardiovascular morbidity and all-cause mortality. A population-based study. Thromb Haemost. 2014; 111(2): 300-307, doi: 10.1160/TH13-07-0567, indexed in Pubmed: 24173039 .

18. Bhat T, Teli S, Rijal J, et al. Neutrophil to lymphocyte ratio and cardiovascular diseases: a review. Expert Rev Cardiovasc Ther. 2013; 11(1): 55-59, doi: 10.1586/erc.12.159, indexed in Pubmed: 23259445.

19. Heinzl H, Kaider A. Gaining more flexibility in Cox proportional hazards regression models with cubic spline functions. Comput Methods Programs Biomed. 1997; 54(3): 201-208, doi: 10.1016/ s0169-2607(97)00043-6, indexed in Pubmed: 9421665.

20. Therneau T (2020). A Package for Survival Analysis in R. R package version 3.1-11. https://CRAN.R-project.org/package=survival.

21. Ommen SR, Gibbons RJ, Hodge DO, et al. Usefulness of the lymphocyte concentration as a prognostic marker in coronary artery disease. Am J Cardiol. 1997; 79(6): 812-814, doi: 10.1016/ s0002-9149(96)00878-8, indexed in Pubmed: 9070569.

22. Zouridakis EG, Garcia-Moll X, Kaski JC. Usefulness of the blood lymphocyte count in predicting recurrent instability and death in patients with unstable angina pectoris. Am J Cardiol. 2000; 86(4): 449-451, doi: 10.1016/s0002-9149(00)00963-2, indexed in Pubmed: 10946041.

23. Widmer A, Linka AZ, Attenhofer Jost CH, et al. Mechanical complications after myocardial infarction reliably predicted using C-reactive protein levels and lymphocytopenia. Cardiology. 2003; 99(1): 25-31, doi: 10.1159/000068448, indexed in Pubmed: 12589119.

24. Dogan NB, Ozpelit E, Akdeniz S, et al. Simple clinical risk score for no-reflow prediction in patients undergoing primary Percutaneous Coronary Intervention with acute STEMI. Pak J Med Sci. 2015; 31(3): 576-581, doi: 10.12669/pjms.313.7484, indexed in Pubmed: 26150847.

25. Núñez J, Miñana G, Bodí V, et al. Low lymphocyte count and cardiovascular diseases. Curr Med Chem. 2011; 18(21): 3226-3233, doi: 10.2174/092986711796391633, indexed in Pubmed: 21671854.

26. Thomson SP, McMahon LJ, Nugent CA. Endogenous cortisol: a regulator of the number of lymphocytes in peripheral blood. Clin Immunol Immunopathol. 1980; 17(4): 506-514, doi: 10.1016/0090-1229(80)90146-4, indexed in Pubmed: 7192197. 
27. Ulich TR, Keys M, Ni RX, et al. The contributions of adrenal hormones, hemodynamic factors, and the endotoxin-related stress reaction to stable prostaglandin analog-induced peripheral lymphopenia and neutrophilia. J Leukoc Biol. 1988; 43(1): 5-10, doi: 10.1002/jlb.43.1.5, indexed in Pubmed: 3275734.

28. Gordon AS. Some aspects of hormonal influences upon the leukocytes. Ann N Y Acad Sci. 1955; 59(5): 907-927, doi: 10.1111/ j.1749-6632.1955.tb45990.x, indexed in Pubmed: 13259358.

29. Hofmann U, Frantz S. Role of lymphocytes in myocardial injury, healing, and remodeling after myocardial infarction. Circ Res. 2015; 116(2): 354-367, doi: 10.1161/CIRCRESAHA.116.304072, indexed in Pubmed: 25593279.

30. Toft P, Svendsen P, Tønnesen E, et al. Redistribution of lymphocytes after major surgical stress. Acta Anaesthesiol Scand. 1993; 37(3): 245-249, doi: 10.1111/j.1399-6576.1993.tb03708.x, indexed in Pubmed: 8517098.

31. Le Campion A, Gagnerault MC, Auffray C, et al. Lymphopenia-induced spontaneous T-cell proliferation as a cofactor for autoimmune disease development. Blood. 2009; 114(9): 1784-1793, doi: 10.1182/blood-2008-12-192120, indexed in Pubmed: 19561321.

32. Linton PJ, Dorshkind K. Age-related changes in lymphocyte development and function. Nat Immunol. 2004; 5(2): 133-139, doi: 10.1038/ni1033, indexed in Pubmed: 14749784.

33. Bessman JD, Gilmer PR, Gardner FH. Improved classification of anemias by MCV and RDW. Am J Clin Pathol. 1983; 80(3):
322-326, doi: 10.1093/ajcp/80.3.322, indexed in Pubmed: 6881096.

34. Fava C, Cattazzo F, Hu ZD, et al. The role of red blood cell distribution width (RDW) in cardiovascular risk assessment: useful or hype? Ann Transl Med. 2019; 7: 581.

35. Salvagno GL, Sanchis-Gomar F, Picanza A, et al. Red blood cell distribution width: A simple parameter with multiple clinical applications. Crit Rev Clin Lab Sci. 2015; 52(2): 86-105, doi: 10.3109/10408363.2014.992064, indexed in Pubmed: 25535770.

36. Allen LA, Felker GM, Mehra MR, et al. Validation and potential mechanisms of red cell distribution width as a prognostic marker in heart failure. J Card Fail. 2010; 16: 230-238.

37. Förhécz $Z$, Gombos T, Borgulya G, et al. Red cell distribution width in heart failure: prediction of clinical events and relationship with markers of ineffective erythropoiesis, inflammation, renal function, and nutritional state. Am Heart J. 2009; 158(4): 659-666, doi: 10.1016/j.ahj.2009.07.024, indexed in Pubmed: 19781428.

38. Pilling LC, Atkins JL, Kuchel GA, et al. Red cell distribution width and common disease onsets in 240,477 healthy volunteers followed for up to 9 years. PLoS One. 2018; 13(9): e0203504, doi: 10.1371/journal.pone.0203504, indexed in Pubmed: 30212481.

39. Su C, Liao LZ, Song Y, et al. The role of red blood cell distribution width in mortality and cardiovascular risk among patients with coronary artery diseases: a systematic review and meta-analysis. J Thorac Dis. 2014; 6: 1429-1440. 